\title{
Modifying Vocational Maturity in Adults with Delayed Career Development: A Life Skills
}

Approach

\section{Caroline A. Manuele}

Many adults experience what LoCascio $(1964,1974)$ has called "late, delayed, or impaired" (p.885) career development. Frequently these adults come from educationally disadvantaged backgrounds and have histories of unemployment or underemployment in low-level, poorly paying jobs. Their career development patterns often reveal limited aspiration and goal striving, previous histories of educational failure, limited use of resources, lack of involvement in career choice, planning, and decision making, and a devaluing of personal traits resulting in low self-esteem (Adkins, Hattauer, Kessler, \& Manuele, 1977). They have delayed career development in the sense that they are not addressing career development tasks that are appropriate for their age. They also experience difficulty coping with many tasks regardless of age appropriateness. (Super, 1957).

Effective counseling programs aimed directly at helping this population with their difficult career development problems are seldom reported in the literature (Dillard, 1980; Goldberg, 1980; Leonard \& Raymond, 1974; Picou \& Campbell, 1975). Vocational behavior and career development literature reviews (Betz, 1971; Fretz \& Leong, 1982; Holcomb \& Anderson, 1977) consistently have identified the need for researchers: (a) to broaden their interests to include out-of-school populations such as dropouts, prisoners, and marginal workers; and (b) to develop and assess specific career development interventions that are aimed at changing the skills of groups who need more nontraditional types of assistance.

The purpose of this study was to explore the effectiveness of a counseling intervention designed specifically to address the needs of disadvantaged or under prepared adults who had demonstrated inconsistent and erratic rates of career development. Another purpose was to determine whether vocational maturity could be modified or increased in a population that has been traditionally difficult for counselors to reach.

Adkins (1970, 1973. 1980) suggested that in order for counselors to meet the needs of this population, interventions were needed that would (a) expose adults systematically to career development tasks that they may not have encountered; (b) provide new socialization experiences and teach more adaptive behavior and skills through a combination of counseling, teaching methods, and learning technologies; (c) provide the means for learners to acquire not only knowledge and understanding but also the behaviors to accomplish the tasks; (d) be designed specifically for the educational, social, and vocational experience level of clients; and (e) incorporate the perspectives of the client population to ensure that their real concerns, feelings, and perceptions are addressed in ways in which they could identify.

Applying these principles to the development of an intervention resulted in the 10-unit Adkins Life Skills Program: Employability Skills Series (Adkins, Wylie, Grothe, Kessler, \& Manuele, 1975) which is currently used in over 300 settings including adult education, Comprehensive Employment Training Act (CETA), community college, and drug and prison rehabilitation programs. The program helps adults learn how to engage in self-appraisal and vocational exploration, use resources, make career-related decisions and choices, obtain employment, apply for jobs, and cope with work adjustment problems. Small group methods are used as an integral part of the learning process. This provides a supportive setting in which fears and anxieties can be dealt with while learning is taking place.

Well-established social learning methods are used in the Life Skills Program to induce behavioral change within the framework of a structured four stage-learning model. These methods include modeling, role playing, social reinforcement, small-step learning, transfer of training, and systematic feedback. Videotapes are used extensively in the program for three purposes: (a) to depict vocational problems by means of dramatic vignettes that focus client attention, stimulate readiness, and increase motivation to learn; (b) to show models of effective behaviors and skills; and (c) to provide feedback to clients about their own performance as they practice new behaviors. Other prepared activities and materials include simulation exercises, articles that introduce basic career development concepts, games that are designed to increase skills, audio recordings, assessment procedures for evaluating interests, abilities, and values, exploratory action projects to be carried out in the community, and methods for introducing occupational role models and information into the classroom. 
The objectives of the Life Skills approach are to confront clients with major career development tasks and to help them acquire the psychosocial skills needed to cope with these tasks. If the program is effective in meeting these objectives, clients should become more involved with their career development and demonstrate greater degrees of competence in coping with career development tasks. Three research questions were formulated in an effort to examine empirically the effect of the Adkins Life Skills approach on participants' career development.

1.Will adults' vocational maturity increase following their participation in the Life Skills Program?

2.Will participants change their attitudes toward their own career development, specifically their belief in the value of coping with career development tasks and their confidence in their ability to do so?

3.How does age, reading grade level, and employment experience affect participants' ability to benefit from the Life Skills Intervention?

\section{METHOD}

\section{Sample}

The participants in this study were 20 adults (17 females, 3 males) from a small, industrial community who volunteered to attend the Adkins Life Skills Program (ALSP). They were recruited from the State Employment Agency and the Adult Education and CETA programs in their community. Before agreeing to attend the program, all participants received a presentation on the nature and purposes of the program and were told about the accompanying study. Their ages ranged from 25 to 53 years with a mean age of 40.8 years. The group was $75 \%$ White and $25 \%$ Black. The majority $(85 \%)$ were unemployed at the time of the study. An analysis of previous employment history indicated that they all held unskilled or semiskilled jobs when they were employed. Most $(75 \%)$ left school at an early age and did not have a high school diploma. Their reading comprehension levels, expressed as grade equivalents, ranged from 6.0 to $12.0+$ with a mean of 9.6.

\section{Design and Procedures}

The quasi-experimental design used in this study was a one-group pretest and posttest design (Campbell \& Stanley, 1963). Before their attendance in the ALSP, clients participated in a 2-hour interview. During this interview their vocational maturity was measured on a pretest basis with the Adult Vocational Maturity Assessment Interview (AVMAI) (Manuele, 1983). A biographical information form was also administered in an interview format to elicit detailed information about clients' demographic characteristics, and their education and employment history. In a separate pretesting session clients' reading comprehension levels were assessed with the Stanford TASK test, Levels I and 11 (Gardner, Callis. Merwin, \& Madden, 1972).

After pretesting clients were assigned to one of two Life Skills groups on the basis of their time and scheduling preferences. They attended two 3-hour sessions per week over a 10-week period of time (for a total of over 60 hours). Sessions were conducted by two trained Life Skills Educators who were experienced in delivering the ALSP to this population. Clients participated in 10 Life Skills Units including:

Who I Am and Where I Want to Go. Clients learn to identify interests, abilities and personal characteristics that have implications for choosing a job or career.

Ten Occupational Fields: How Do I Explore Them? Clients explore different occupational areas, jobs, and work settings and learn to analyze and evaluate information about jobs or careers that interest them. 
Jobs and Training: Beginning the Search. Clients acquire skills to use basic sources of information about jobs, and about educational and training programs by learning to interpret classified advertisements, use the telephone, and write formal letters of application.

Employment Agencies and Personal Contacts. Clients identify personal contacts who are useful for obtaining jobs and learn strategies for using public and private employment agencies.

Choosing a Good Job for Myself. Clients are assisted with formulating vocational alternatives, developing behavior for vocational exploration, and learning decision-making skills.

The Job Interview: How To Be Effective. Clients learn how to use verbal and nonverbal communication skills in order to present themselves positively in an employment interview.

After finishing the Life Skills Program, clients participated in another 2-hour interview, during which their vocational maturity was measured again on a posttest basis with the AVMAI.

\section{Instrument Development}

Published vocational maturity measures were reviewed and found to he inappropriate for use with an adult, out-of-school population with poor literacy skills. They were inadequate for this population for several reasons: (a) many of the constructs in existing measures fail to reflect the type of social and psychological experiences adults in these groups have (LoCascio, 1974); (b) they require good reading ability and test-taking skills; (c) they only provide a global estimate of vocational maturity without identifying the specific areas that need intervention (Smith, 1975); and (d) they were initially developed for adolescent, middle-class populations. Therefore, an instrument was developed for this study.

The AVMAI, which assesses attitudinal, cognitive, and behavioral aspects of vocational maturity, consists of a series of structured interview questions with a detailed content scoring manual. The interview takes about 1 to 1 1/2 hours to administer. The following are examples of interview questions included in the AVMAI:

- Do you have some abilities that you think would be valuable to an employer? (Interests and Abilities scale);

- Do you think most people can choose the type of work they do, or do they have to take whatever they can get? (Concern with Choice scale);

- Suppose you hear about an occupation or career that sounded interesting to you. What would you do to learn more about it? (Exploring Occupations scale); and

- Do you have any plans for getting more education or training? (Orientation to Education scale)

Responses to each question in the AVMAI are rated on numerical scales that include a definition of the scoring criteria and a representative verbatim response. Responses that indicate vocationally immature behavior earn lower scores on the scale. The 120 items yield scores for eight scales that assess an individual's ability to cope with tasks associated with choosing, preparing for, and entering an occupation. The eight scales in the AVMAI are:

Orientation to Education. Assesses attitudes toward education, knowledge of education and training opportunities, educational plans, and achievements.

Orientation to Work. Examines attitudes toward work, responsibility for obtaining employment, job satisfaction and dissatisfaction factors, and plans for future employment.

Concern with Choice. Assesses attitudes toward choice and measures crystallization, wisdom, realism, and accessibility of choice.

Self-Appraisal:Interests and Abilities. Measures attitudes toward self- appraisal, knowledge of interests and abilities, and matching of individual traits to occupational alternatives.

Self-Appraisal: Personality Characteristics. Clarity of self-concept is assessed by examining knowledge of personal characteristics, strengths, weaknesses, and attitudes about self.

Self-Appraisal: Values. Identifies personal and work-related values, attitudes, and progress made toward setting and attaining life goals. 
Exploring Occupations. Assesses knowledge of preferred occupations in the areas of duties, salary, education, training requirements, employment, and advancement opportunities.

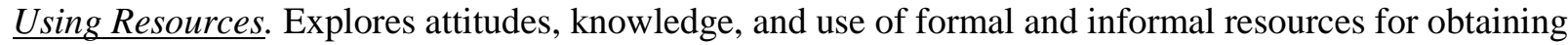
employment and training with emphasis on classified advertisements, employment agencies, letters of inquiry, and the telephone.

The AVMAI also measures attitudes toward coping with career development tasks. Of the 30 items, 12 assess participants' belief in the value of accomplishing specific tasks and 18 are included that assess participants' confidence in their ability to cope with these tasks.

The AVMAI was initially developed and pilot tested with over 60 adults from adult education and CETA programs whose demographic characteristics were similar to the participants in this study. Content validity was established by reviewing the items and scoring criteria with three psychologists who were experts in tile definition and measurement of vocational maturity. Internal consistency reliability estimates for each of the eight scales were $.72, .78, .77, .82, .72, .52, .69$, and .79 with a total measure reliability of .91 . Reliability estimates for the items that formed attitudinal subscales in the AVMAI were .68 and. 74. Interrater reliability was determined by having three raters score 10 pretest and 10 posttest AVMAI protocols. The percentage of rater agreement between all three, raters for each item was then calculated and resulted in a rater agreement of $88 \%$ for the entire measure.

\section{RESULTS AND DISCUSSION}

\section{Vocational Maturity Scores}

The first research question was concerned with examining the effectiveness of the Life Skills intervention for increasing vocational maturity. Means and standard deviations on pretest and posttest AVMAI scores were first computed for the two Life Skills groups. After an analysis of variance showed that there were no significant differences between the two groups, participants in the two groups were treated as one experimental group for all subsequent data analyses.

Dependent $t$ tests were performed to test for the significance of the differences between combined group pretest and posttest scores on each of the eight AVMAI scales (Hays, 1973). As indicated in Table 1, clients' scores on each of the scales increased considerably after their participation in the Life Skills intervention. The results of the t tests, also shown in Table 1, indicate that the difference between scores were significant at the .001 level. The results indicate that clients' vocational maturity scores did increase following their participation in the Life Skills program.

\section{Attitude Toward Career Development}

The second research question examined the effect of the Life Skills intervention on participants' attitudes toward their own career development. These attitudes were defined as Belief in the Value of accomplishing career development tasks and Confidence in Self and one's ability to cope successfully with these tasks. To determine if there were any significant changes on these variables, mean pretest and posttest scores were computed on items in the AVMAI that assessed these attitudes. The data in Table 2 show that the mean scores did increase after the Life Skills intervention. The results of the dependent t tests, also shown in Table 2, indicate that the differences were significant (.001).

\section{Influence of Age, Reading Level, and Work Experience}

The third research question examined the influence of age, reading grade level, and months of work experience on clients' vocational maturity scores after their participation In the Life Skills intervention. Pearson correlations were computed to examine the relationship between each of these variables and the participants' posttest AVMAI scores. 
Table 3 shows that age and work experience were found to be significantly related to higher vocational maturity scores on only two of the eight scales: Orientation to Work correlated with age $(\mathrm{r}=.40)$ and with work experience $(\mathrm{r}=.41)$; Self-Appraisal: Interests and Abilities correlated with age $(\mathrm{r}=.53)$ and with work experience $(\mathrm{r}=.41)$. The results imply that age and work experience were not, in general, related to higher posttest scores on the AVMAI. Younger clients' scores increased as did those of older clients except in two areas in which additional life and work experience may have been influential. Older clients may have developed, because of their age, more mature attitudes and concern for employment- related issues with which they were able to identify more distinctly during their participation in the program. They also may have, as a result of age, more interests and abilities that the intervention was able to help identify and define.

The relationship between reading scores and posttest AVMAI scores is also shown in Table 3. Reading level was significantly related to higher AVMAI scores on all scales except one, Values ( $\mathrm{r}-.31)$. Clients with better literacy skills were able to achieve higher posttest scores on the vocational maturity measure used in this study. This finding suggests that these clients were able to gain more from the intervention than those with less reading ability.

TABLE 2

Protest and Posttest Scores and Values of $t$ for AVMAI

Attitudinal Variables $(n=20)$

\begin{tabular}{|c|c|c|c|c|c|c|}
\hline \multirow[b]{2}{*}{ Variable } & \multicolumn{2}{|c|}{ Pretest } & \multicolumn{2}{|c|}{ Posttest } & \multirow{2}{*}{$\frac{\text { Mean }}{\text { Change }}$} & \multirow{2}{*}{$\mathrm{t}^{\mathrm{b}}$} \\
\hline & Mean & $\underline{S D}$ & Mean & $\underline{S D}$ & & \\
\hline a & & & & & & \\
\hline Belief in Value (12) & 21.00 & 5.75 & 30.75 & 7.14 & 9.75 & $7.72 *$ \\
\hline Confidence in Self (18) & 20.10 & 8.40 & 35.55 & 9.41 & 15.45 & $8.42 *$ \\
\hline \multicolumn{7}{|l|}{$\bar{a}$} \\
\hline \multicolumn{7}{|l|}{ Number of items. } \\
\hline \multicolumn{7}{|l|}{$\mathrm{b}$} \\
\hline$d f=19$ & & & & & & \\
\hline$*_{p}>.001$ & & & & & & \\
\hline
\end{tabular}

TABLE 3

\section{Correlations between Age, Reading Grade Level, Months of Employment and AVMAI Posttest Scores $(n=20)$}

\begin{tabular}{|c|c|c|c|}
\hline Scale & $\underline{\text { Age }}$ & $\begin{array}{r}\text { Reading } \\
\text { Grade Level }\end{array}$ & $\underline{\text { Months of }}$ \\
\hline Orientation to Education & -.12 & $.55 * * *$ & .01 \\
\hline Orientation to Work & $.40 *$ & $.49 * *$ & $.41 *$ \\
\hline Concern with Choice & -.13 & $.52 * *$ & -.09 \\
\hline \multicolumn{4}{|l|}{ Self-Appraisal: } \\
\hline Interests and Abilities & $.53 * * *$ & $.60 * * *$ & $.41 *$ \\
\hline Personality Characteristics & -.23 & $.37 *$ & -.25 \\
\hline
\end{tabular}




$\begin{array}{llll}\text { Values } & -.15 & .31 & -.03 \\ \text { Exploring Occupations } & .26 & .76^{* * *} & .29 \\ \text { Using Resources } & .14 & .47^{* * *} & .14 \\ \text { Total AVMAI Score } & .05 & .69^{* *} & .05\end{array}$

$$
\begin{gathered}
* p>05 . \\
* * p>.01 . \\
* * * P>.001 .
\end{gathered}
$$

\section{Qualitative Results}

What types of career development and vocational maturity problems did clients in this study actually exhibit, and what kind of changes occurred with respect to these problems as a result of their exposure to the intervention? These questions were addressed by examining clients' responses to specific items in the AVMAI.

Pretest responses. These responses indicated that the participants had not resolved many of the tasks of career development associated with preparing for, entering, and stabilizing in an occupation. Many believed they had failed at prior attempts to obtain education and training and $65 \%$ expressed little or no confidence in their ability to learn. Acceptance of responsibility for obtaining employment showed that only $21 \%$ had engaged in active, sustained efforts to find a job. Although career choice is the focus of most career development theories, career choice for many of these adults was nonexistent. Most of them (95\%) had not made choices about their work. Career choice, they believed, was only possible for those with more education and training than they had.

An examination of participants' levels of self-awareness showed that vocationally related interests and abilities were fairly undefined and unrelated to occupations in which participants said they were interested. Descriptions of personal characteristics were limited and often self-negating (75\%). There were varying degrees of involvement with setting and achieving goals, but most participants $(60 \%)$ were extremely unsatisfied with the progress they had made in life up to this point. Occupational exploration was limited by participants' lack of knowledge about resources to use for exploration and by their lack of participation in many active information-seeking behaviors. Responses to items that assessed planning or future orientation, a major aspect of vocational maturity, showed that these adults engaged in very little planning activity.

Posttest responses .Posttest responses on the AVMAI indicated that participants became more confident in their ability to learn to develop, and to implement plans for enrolling in educational programs. After the intervention $40 \%$ of the group actually enrolled in an educational program of some type. Participants also became more involved with efforts to obtain employment. At the time of the posttest $55 \%$ were actually employed compared with $15 \%$ who were employed at the time of the pretest.

Participants became more aware of the issues involved in career choices. At the end of the intervention $50 \%$ of the group had fairly firm choices and their choices became more specified and focused; $30 \%$ had fashioned reasonable alternatives for themselves, and $20 \%$ needed more time and exploration before they were ready to choose. Clients also showed improvement in their ability to define their interests (70\%) and abilities $(80 \%)$ and to relate them to their occupational preferences. Their comments about themselves reflected greater self-esteem. A majority (75\%) demonstrated significant increases in the amount and specificity of occupational information they had. Their knowledge of which resources to use increased, and they reported an increase in confidence in their ability to locate these resources in their community. 


\section{SUMMARY AND CONCLUSION}

The results of this study indicate that clients did make significant increases in vocational maturity following their participation in the Life Skills Program. They also demonstrated attitudinal change especially toward becoming more involved in their own career development. These findings may be attributed to two factors: (a) using an intervention that was designed to meet the cognitive, affective, and motivational needs of clients who were undereducated or vocationally unprepared; and (b) evaluating the effects of the intervention with an appropriate vocational maturity measure.

There are several implications of this study's findings for counselors. First, the results support the effectiveness of the ALSP and other programs of its type for use with clients with delayed or impaired career development. Second, the results indicate that vocational maturity is a characteristic that can be increased or developed in clients if appropriate training is provided. The study also provides evidence for the usefulness of an interview format for the assessment of vocational maturity. The format is particularly valuable for persons who, because of their poor literacy skills, have problems with paper-and-pencil tests. The interviewer can determine if questions are understood, can probe if there are inadequate responses, and can determine, from the qualitative responses, what a client's intervention needs are.

These findings, however, must he interpreted in the context of some of the limitations of the study, including the small number of participants, the absence of a control group, the voluntary nature of participation, and the use in this study of a new measure of vocational maturity in an early state of development. The significant increases in posttest scores could, because of these limitations, be attributed to other factors, including the possibilities that learning may have occurred from the pretest itself, that changes occurred because of time and maturation, that statistical regression in the test-retest situation occurred, and that clients may have been influenced by the knowledge that they were participating in a study. Future research needs to address these limitations and also to include long-term follow-up studies to determine if these changes persist over time with this population.

The changes reported in this study also represent small developmental gains when compared with the enormity of the career development problems experienced by these adults. Comprehensive solutions for these problems still need to include education, occupational training, and access to employment opportunities. These results indicate, however, that counselors can begin to meet the needs of clients who require nontraditional assistance if interventions, instruments, and counseling practices can be developed and used that match the nature of the career development problems that clients experience.

\section{REFERENCES}

Adkins, W.R. (1970). Life skills: Structured counseling for the disadvantaged. Personnel and Guidance Journal . 49. 108-116.

Adkins, W.R. (1973). Life skills education for adult learners. Adult Leadership, 22, 55-58.

Adkins. W. R. (19MI). Life skills counseling. In R. Herink, (Ed.), The psychotherapy handbook. 344-118. New York, NY: New American Library.

Adkins, W. R., Hattauer, E., Kessler, M., \& Manuele, C. (1977). Where they hurt: A study of the life coping problems of unemployed adults. New York, NY: Teachers College, Columbia University.

Adkins, W. B., Wylie, P., Grothe. M., Kessler, M., \& Manuele, C. (1975). Adkins life skills program: Employability skills series. New York, NY: Psychological Corporation.

Betz. E. (1971). Vocational behavior and career development, 1970. A review. Journal of Vocational Behavior, 11. 129-152.

Dillard, J. M. (1980). Some unique career behavior characteristics of blacks: Career theories, counseling practices and research. Journal of Employment Counseling, 6, 288-298.

Fretz, B.R., \& Leong, F.T. (1982). Vocational behavior and career development, 1981: A review. Journal of Vocational Behavior, 21, 123-163.

Gardner, E.F., Callis, R., Merwin, J.C. \& Madden. R. (1972). Stanford TASK test of academic skills. New York, NY: Harcourt Brace Jovanovich.

Goldberg, J. (1980). Counseling the adult learner: A selective review of the literature. Adult Education, 30, 67-81. 
Hays, W. L. (1973). Statistics for the social sciences. 2nd edition. New York, NY: Holt, Rinehart and Winston.

Holcomb, W. R., \& Anderson. W. P. (1977). Vocational guidance research. Journal of Vocational Behavior, 10, 341-3-16.

Leonard, G.E., \& Raymond, W. (1974). Career education: Disadvantaged students. Columbus, OH: National Center for Research in Vocational Education. Ohio State University. (ERIC Document Reproduction Service No. ED 086 798)

LoCascio, R. (1964). Delayed and impaired vocational development: A neglected aspect of vocational development theory. Personnel and Guidance Journal. 42. 885-887.

LoCascio, R. (1974).The vocational maturity of diverse groups: Theory and measurement. In D.E. Super (Ed.). Measuring vocational maturity for counseling and evaluation. 123-133). Washington. DC: National Vocational Guidance Association.

Manuele, C. (1983). The development of measure of vocational maturity for adults with delayed career development. Journal of Vocational Behavior, 23, 45-63.

Picou, J. S., \& Campbell. R. E. (1975). (Eds.). Career behavior of special groups. Columbus, Oh: Charles E. Merrill.

Smith, E.J. (1975). Profile of the Black individual in vocational literature. Journal of Vocational Behavior, 6. 41-59.

Super, D.E. (1957). Psychology of careers. New York, NY: Harper \& Row.

\section{From}

Manuele, C. (1984). Modifying vocational maturity in adults with delayed career development. Vocational Guidance Quarterly. December, 101-112. 